\title{
Decision-making Competence in Older Adults: A Rosy View from a Longitudinal \\ Investigation
}

\author{
Fabio Del Missier \\ University of Trieste \\ Patrik $\underline{\text { Hansson }}$ \\ Umeå University \\ Andrew M. Parker \\ RAND Corporation
}

Wändi Bruine de Bruin

University of Leeds and Carnegie Mellon University

Timo Mäntylä

Stockholm University

Author Note. Fabio Del Missier, Department of Life Sciences, University of Trieste, Trieste, Italy; Patrik Hansson, Department of Psychology, Umeå University, Umeå, Sweden; Andrew M. Parker, RAND Corporation, Pittsburgh, Pennsylvania, USA; Wändi Bruine de Bruin, Leeds University Business School, University of Leeds, Leeds, United Kingdom, and Department of Engineering and Public Policy, Carnegie Mellon University, Pittsburgh, Pennsylvania, USA; Timo Mäntylä, Department of Psychology, Stockholm University, Stockholm, Sweden. Corresponding author: Fabio Del Missier (delmisfa@units.it). This publication is based on data collected in the Betula prospective cohort study, Umeå University, Sweden. The Betula Project is supported by Knut and Alice Wallenberg foundation (KAW) and the Swedish Research Council (K2010-61X-21446-01). This research was supported by the Swedish Riksbankens Jubileumsfond with a research grant awarded to Timo Mäntylä for the project Aging and 
decision-making competence (P09-0568:1). Wändi Bruine de Bruin’s work was also funded by Riksbankens Jubileumsfond in the program on Science and Proven Experience. The authors declare no conflict of interest. Preliminary results of this study were presented at the $21^{\text {st }}$ International Association of Gerontology and Geriatrics Conference in San Francisco and at the Subjective Probability, Utility, and Decision Making 2019 conference in Amsterdam.

In press, Psychology and Aging

(C) 2019, American Psychological Association. This paper is not the copy of record and may not exactly replicate the final, authoritative version of the article. Please do not copy or cite without authors' permission. The final article will be available, upon publication, via its DOI: https://doi.org/10.1037/pag0000443 


\begin{abstract}
Cross-sectional studies have suggested age-related differences in decision-making competence, but these differences may also reflect cohort-related effects. We present a longitudinal study of age-related changes over five years in older adults (aged 60-85), for three important aspects of decision-making competence: Resistance to Framing, Applying Decision Rules, and Resistance to Sunk Costs. Findings show small age-related longitudinal declines in Resistance to Framing, but no decline in Applying Decision Rules or Resistance to Sunk Costs. Results also indicate that individuals' decision-making competence after five years is significantly related to their initial decision-making competence assessment and that the contribution of crystallized abilities to decision making in older adults is greater than previously thought.
\end{abstract}

Keywords: decision-making competence, decision making, cognitive aging, individual differences, cognitive reserve 
Populations are aging worldwide (European Commission, 2012; United Nations, 2017), and older adults face important life decisions for which they need decision-making competence (Bruine de Bruin, Parker, \& Fischhoff, 2012). Decision-making competence is defined as the set of abilities that are conducive to consistent judgments and accurate decisions, as prescribed by normative theories of decision making (Bruine de Bruin et al., 2012; Strough, Parker, \& Bruine de Bruin, 2015), and it is associated with better decision-related life outcomes (Bruine de Bruin, Parker, \& Fischhoff, 2007; Parker, Bruine de Bruin, Fischhoff, \& Weller, 2018).

Research in cognitive aging suggests that some aspects of older adults' decision-making competence could be undermined by age-related declines in fluid cognitive abilities, such as processing speed, working memory, and reasoning (e.g., Bruine de Bruin et al., 2012; Del Missier et al., 2017; Finucane, \& Gullion, 2010; Finucane, Mertz, Slovic, \& Schmidt, 2005). However, as indicated below, existing evidence comes from a rather small number of studies with cross-sectional research designs, which may have inflated age-related differences. Therefore, a longitudinal investigation of decision-making competence is needed.

Unlike the field of decision making, the field of cognitive aging is rich with longitudinal studies (e.g., Fleischman, Wilson, Gabrieli, Bienias, \& Bennett, 2004; Josefsson, de Luna, Pudas, Nilsson, \& Nyberg, 2012; Salthouse, 2014a; Schaie, 2013), whose results can be compared with cross-sectional assessments (e.g., Salthouse, 2014b). For instance, one longitudinal assessment has shown different age-related patterns in episodic and semantic memory as compared to the cross-sectional evaluation, with age-related declines starting later and, for semantic memory, being less pronounced (Rönnlund, Nyberg, Bäckman, \& Nilsson, 2005). Discrepancies between longitudinal and cross-sectional studies of memory may partially reflect cohort differences in education and other characteristics (Rönnlund et al., 2005). Thus, longitudinal studies of decision-making competence might also provide a different picture than previous cross-sectional investigations. 
In recent years, seminal studies have focused on developing valid and reliable measures of decision-making competence like the Adult Decision-Making Competence battery, which is grounded in the behavioral decision-making literature (Bruine de Bruin et al., 2007; Parker \& Fischhoff, 2005). Three important aspects of decision-making competence assessed in this battery and also investigated in our study are: (a) the ability to express consistent preferences despite superficial variations in the description of choice options (Resistance to Framing), (b) the ability to correctly apply procedures for choosing among multiple options (Applying Decision Rules), and (c) the ability to ignore irrecoverable and hence irrelevant past costs (Resistance to Sunk Costs). Indeed, a good decision-maker should not be swayed by the way in which the same options are described, thus resisting framing effects (Tversky \& Kahneman, 1981). For instance, in the case of attribute framing, a package of meat should be evaluated similarly, independent of whether it is described as $80 \%$ lean or as $20 \%$ fat (Levin \& Gaeth, 1988). Decision makers should also be able to correctly apply decision rules to choose among sets of options (see e.g., Payne, Bettman \& Johnson, 1993). For instance, the 'elimination by aspects' rule requires that decision makers eliminate from consideration all the options that do not meet the threshold value on the most important attribute (say, price), subsequently eliminate options that do not meet the threshold value on the second most important attribute (say, quality), and so on (Tversky, 1972). Finally, according to theories of rational decision making (Edwards, 1954), decision makers should ignore irrecoverable past investments (also referred to as 'sunk costs') and base decisions only on expectations for future outcomes. For example, if someone has already paid to see a movie on a hotel pay TV but notices that a preferred movie is offered on a free channel, the irrecoverable cost should be ignored and a switch should be made (Bruine de Bruin et al., 2007). However, decision makers often fail to do so because they are concerned about "wasting" their irrecoverable losses (Arkes \& Blumer, 1985). 
A small subset of cross-sectional studies on decision-making competence has focused on age-related differences (e.g., Bruine de Bruin et al., 2012; Del Missier, et al., 2013, 2017; Finucane \& Gullion, 2010; Finucane et al., 2005; Rosi, Bruine de Bruin, Del Missier, Cavallini, \& Russo, 2019). These cross-sectional investigations have shown that older adults perform worse than younger participants on tasks like Resistance to Framing and Applying Decision Rules (see also Besedeš, Deck, Sarangi, \& Shor, 2012; Kim, Goldstein, Hasher, \& Zacks, 2005), which has been in part explained by age-related differences in fluid cognitive skills, working memory, and executive control (e.g., Bruine de Bruin et al., 2012; Del Missier et al., 2013, 2017; Rosi et al., 2019; see also Del Missier, Mäntylä \& Nilsson, 2015). Interestingly, older adults tend to perform better than younger adults on other aspects of decision-making competence, such as Resistance to Sunk Costs (Bruine de Bruin et al., 2012; Bruine de Bruin, Strough, \& Parker, 2014; Eberhardt, Bruine de Bruin, \& Strough, 2019; Strough, Mehta, McFall $\&$ Schuller, 2008). Resistance to Sunk Costs appears to be more strongly related to crystallized cognitive skills or learned knowledge (Del Missier et al., 2013; Eberhardt et al., 2019; Fennema \& Perkins, 2008; Larrick, Morgan \& Nisbett, 1990), which tend to improve over adults' lifetime, than to fluid cognitive skills, which tend to decrease over adults' lifetime.

However, given that these results have been obtained from cross-sectional investigations, the reported age differences may reflect cohort effects in addition to developmental changes (e.g., Lindenberger, von Oertzen, Ghisletta \& Hertzog, 2011; Rönnlund et al., 2005). To the best of our knowledge, the only published longitudinal study of decision-making competence involved a young adult sample that was followed between the ages of 19-30 years (Parker et al., 2018). That study showed the stability of the overall decision-making competence construct in young adults, but did not address changes in aspects of older adults' decision-making competence or the cognitive underpinnings of older adults' decision-making competence. To start filling these knowledge gaps, we carried out a longitudinal study with a Swedish sample 
of older adults (age 60-85). Our aims were (a) to characterize longitudinal changes in main aspects of decision-making competence and (b) to identify the cognitive predictors of these aspects of decision-making competence in order to shed light on their cognitive underpinnings.

Our investigation took place as part of the Betula project, a large-scale Swedish study on aging, memory, and dementia. The Betula project started in 1988, with participants being tested in six waves, conducted every 5 years. Betula samples were taken from the population of Umeå, a city in northern Sweden, with a stratified random sampling plan to obtain representativeness to the Swedish national population (Nilsson et al, 1997, 2004). We added decision-making competence measures to the Betula data collection in the fifth and sixth testing waves (henceforth referred to as Time 1 and Time 2). Thus, five years passed between these two assessments of decision-making competence. In the present investigation, we focused on longitudinal changes in decision-making measures that showed significant age-related differences in previous cross-sectional studies (Bruine de Bruin et al., 2012; Del Missier et al., 2013, 2017): Resistance to Framing, Applying Decision Rules, and Resistance to Sunk Costs, as well as with tests of fluid and crystallized cognitive skills. As previously explained, these tests measure important components of competence, which are have been deemed relevant to real-world decision-making (Bruine et al., 2007; Parker \& Fischhoff, 2005).

In the present study, we expect to observe small age-related differences, given findings in cognitive aging showing that longitudinal age differences tend to be smaller than crosssectional ones (Rönnlund, et al., 2005; Salthouse, 2014b). Namely, we expect small longitudinal declines in Resistance to Framing and Applying Decision Rules, mainly related to the decline of fluid cognitive skills (Bruine de Bruin et al., 2012; Del Missier et al., 2013, 2017), and improvement or stability in Resistance to Sunk Cost, possibly related to crystallized cognitive skills (Del Missier et al., 2013). It is worth noting that longitudinal studies of memory in the Betula project observed performance declines even after 55 years of age (e.g., Rönnlund 
et al., 2005), thus justifying the expectation of longitudinal differences even in our older adult sample.

\section{Method}

\section{Participants}

Our sample consisted of 303 Swedish adults who completed the Adult Decision-Making Competence questionnaire at Time 1, whose age was between 60 and 85 years at Time 2 . Almost all Time 1 participants $(92 \% . \mathrm{n}=280)$ returned the questionnaire also at Time 2 . Twenty-three participants did not complete the Adult Decision-Making Competence questionnaire at Time 2 and were treated as having dropped out. No significant attrition effect was observed for age $\left(t=1.79\right.$, df $\left.=301, p=.08 ; \mathrm{M}_{\text {sample }}=70.92, \mathrm{M}_{\mathrm{drop}}=68.04\right)$, cognitive impairment as assessed by the Mini Mental State Examination (MMSE) at Time $2(t=-1.63$, $\left.\mathrm{df}=301, p=.10 ; \mathrm{M}_{\mathrm{sample}}=27.87, \mathrm{M}_{\mathrm{drop}}=28.48\right)$, years of education $(t=-1.09, \mathrm{df}=297, p=$ $\left..28 ; \mathrm{M}_{\text {sample }}=12.60, \mathrm{M}_{\text {drop }}=13.45\right)$, or sex (Fisher exact test: $p=.83 ; \% \mathrm{~F}_{\text {drop }}=7.01 \% \% \mathrm{M}_{\text {drop }}=$ $8.22 \%$ ). Data from two participants were discarded because they left the decision-making tests at Time 2 blank. Thus, the final sample consisted of 278 participants, including 99 adults aged 60-69 years $\left(\mathrm{M}_{60-69}=62.58\right), 117$ aged $70-79\left(\mathrm{M}_{70-79}=72.61\right)$, and 62 aged 80 or older $\left(\mathrm{M}_{>79}=\right.$ 81.05) at Time 2.

\section{Procedure}

Informed consent was obtained from all participants and the study was approved by the ethical committee of Umeå University. Participants were screened for dementia, sensory impairments, mental retardation, and a native tongue other than Swedish (for further details concerning sampling, recruitment, and inclusion criteria see Nilsson et al., 1997, 2004). They also underwent a health assessment session, followed by a cognitive testing session on a 
different day. The cognitive testing session included standard tests of fluid and crystallized cognitive abilities (Block Design and SRB, described in the next section). After the cognitive testing session, participants completed the Swedish version of the Adult Decision-Making Competence tasks (http://www.sjdm.org/dmidi/Adult___Decision_Making_Competence.html) and other measures at home. They were provided with detailed written instructions and examples for each task, and they completed the decision-making tasks alone and without external aids following the pre-specified task order (see also Del Missier et al., 2013, 2017).

\section{Measures}

WAIS-R Block Design. The block design test is a well-established measure of fluid intelligence that involves the manipulation of cubes to match a series of patterns presented in ascending order of difficulty. The task was administered in accord with the WAIS-R-manual (Wechsler, 1981) and raw scores were used as the performance measure.

Vocabulary test (SRB). SRB is a 30-item multiple-choice Swedish synonym test (SRB; Dureman, 1960) used to assess crystallized ability. Participants' task is to select a synonym of the target word from among five alternatives. Seven minutes are allotted for test completion. The total number of correctly identified synonyms is the performance score (Nilsson et al., 1997; Rönnlund \& Nilsson, 2006).

Resistance to Framing. This task includes seven risky-choice framing problems and seven attribute framing problems taken from the literature (Bruine de Bruin et al., 2007). Each risky-choice problem presents two equivalent choices between a sure thing and a risky option, with one framed in terms of gains and the other in terms of losses. For example, one of these problems describes a pesticide threatening the lives of 1,200 endangered animals. The gain version presents a choice between (A) saving 600 endangered animals for sure and (B) a 75\% chance that 800 animals will be saved, and a $25 \%$ chance that no animals will be saved. The 
corresponding loss version offers a choice between (A) losing 600 animals for sure and (B) a $75 \%$ chance that 400 animals will be lost, and a $25 \%$ chance that 1,200 animals will be lost (Schneider, 1992). Responses are given on a 6-point scale $(1=$ definitely would choose A; $6=$ definitely would choose B) to require the expression of a preference between the two options. Each attribute framing problem asks participants to rate positive and negative descriptions of normatively equivalent options. For example, in one of these problems a package of ground beef is described as $80 \%$ lean in the positive version and as $20 \%$ fat in the negative version (Levin \& Gaeth, 1988), and participants are asked to rate the quality of ground beef on a 6point scale $(1=$ very low; $6=$ very high $)$. The positive and negative frames appear in separate sets with different item orders and are separated by other decision-making tasks. Performance is reflected in the mean absolute difference between ratings for the loss and the gain versions across items, and the final score is reversed so that a higher score represents higher resistance to framing.

Applying Decision Rules. This task measures the ability to correctly apply decision rules to choices among options with multiple attributes (Bruine de Bruin et al., 2007; Payne et al., 1993), such as consumer products or insurance plans. Participants are presented with 10 different multi-attribute decision problems involving choices between fictitious DVD players with different features (such as sound quality). For each problem, participants are asked to select one or more options according to a different decision rule (elimination by aspects, lexicographic, satisficing, equal weights, etc.; see Payne et al., 1993) from a table showing numeric ratings of features. The decision rule to be applied in the specific problem is presented by providing participants with a short written description. The final score in this task represents the proportion of responses across items that reflect normatively correct answers that would have been obtained from an errorless application of the prescribed decision rules. 
Resistance to Sunk Costs. This task measures the ability to choose options with the best future outcomes while ignoring irrecoverable past investments or "sunk costs" (Bruine de Bruin et al., 2007). The Resistance to Sunk Costs task comprises of 10 problems that describe a situation in which someone could go on with a prior course of action (thus incorrectly honoring sunk costs) or move on to a rationally better course of action. For instance, one item presents a choice between watching a movie on the pay tv of a hotel room for which $\$ 6.95$ was already paid (sunk cost option) and watching a more preferred movie on the free TV shown at the same time. For each problem, participants are asked to rate their relative preference for the sunk cost option $(=1)$ versus the normatively correct option to discontinue the investment $(=6)$. Performance is measured by the average of the ratings across the 10 items, with higher scores expressing greater resistance to sunk costs.

\section{Results}

\section{Data Analysis}

The a-priori sample size for the detection of a small effect size $(d=.2)$ with power 90 and an $\alpha$ level of .05 in a two-tailed paired $t$ test was 265 , indicating that each of the paired $t-$ tests we performed on decision-making measures in our sample had good statistical power (although other tests used may have been less powerful). Table 1 presents descriptive statistics for all the measures.

Table 1

Descriptive Statistics for All the Measures at the First (Time 1) and Second (Time 2) Testing Waves Valid Mean Median Min Max $\quad$ Std. Skewness Kurtosis Measure N Dev.

\begin{tabular}{lllllllll}
\hline Age (years) Time 2 & 278 & 70.92 & 70.00 & 60.00 & 85.00 & 7.41 & 0.04 & -1.06 \\
Education (years of) & 274 & 12.56 & 12.50 & 6.00 & 26.00 & 3.91 & 0.25 & -0.36
\end{tabular}


MMSE Time 2

Resistance to Framing Time1

Resistance to Framing Time 2

Applying Decision Rules Time 1

Applying Decision Rules Time 2

Resistance to Sunk Costs Time 1

Resistance to Sunk Costs Time 2

Block Design Time 1

Block Design Time 2

Vocabulary Test (SRB) Time 1

Vocabulary Test (SRB) Time 2

$\begin{array}{llllllll}278 & 27.87 & 28.00 & 21.00 & 30.00 & 1.72 & -1.25 & 1.98 \\ 278 & 3.93 & 4.00 & 2.50 & 4.93 & 0.51 & -0.40 & -0.27 \\ 276 & 3.83 & 3.79 & 1.79 & 5.00 & 0.57 & -0.27 & 0.13 \\ 278 & 0.72 & 0.73 & 0.27 & 1.00 & 0.16 & -0.24 & -0.49 \\ 273 & 0.72 & 0.73 & 0.07 & 1.00 & 0.18 & -0.85 & 0.71 \\ 278 & 4.59 & 4.60 & 2.50 & 6.00 & 0.65 & -0.26 & -0.29 \\ 278 & 4.60 & 4.60 & 2.50 & 6.00 & 0.66 & -0.33 & -0.26 \\ 278 & 29.13 & 29.00 & 2.00 & 49.00 & 9.29 & -0.06 & -0.37 \\ 277 & 26.15 & 25.00 & 4.00 & 47.00 & 9.21 & 0.14 & -0.40 \\ 278 & 24.52 & 25.00 & 13.00 & 30.00 & 3.17 & -0.86 & 0.67 \\ 278 & 24.18 & 25.00 & 10.00 & 30.00 & 3.53 & -1.08 & 1.44\end{array}$

Note. The sample was composed by 144 females (52\%) and 134 males (48\%). Reliabilities of the tests are as follows: Block Design $=.81$ (Rönnlund, \& Nilsson, 2006), Vocabulary Test $(\mathrm{SRB})=.86$ (Rönnlund \& Nilsson, 2006), MMSE $=.80-.95$ (Tombaugh \& McIntyre, 1992). Reliabilities of the decision-making measures in our two testing waves are as follows: Resistance to Framing Time $1=.57$, Applying Decision Rules Time $1=.76$, Resistance to Sunk Costs Time $1=.44$, Resistance to Framing Time $2=.65$, Applying Decision Rules Time $2=$ .76 , Resistance to Sunk Costs Time $2=.53$.

\section{Longitudinal Changes in Decision-making Competence}

Resistance to Framing. Age at Time 2 was negatively correlated with performance on Resistance to Framing $(r=-.17, p<.01)$, and a slight but significant longitudinal performance decrease was observed over five years (paired $t=2.48, d f=275, p=.01, M_{T 1}=3.93 S D_{T 1}=$ $\left.0.51, M_{T 2}=3.83 S D_{T 2}=0.57\right)$. We estimated a latent change score model (McArdle, 2009) to assess whether age is associated with the slope of change in Resistance to Framing. The model was estimated with the maximum likelihood method fixing some coefficients at 1 (as shown in Figure 1) and mean substitution of missing data. 


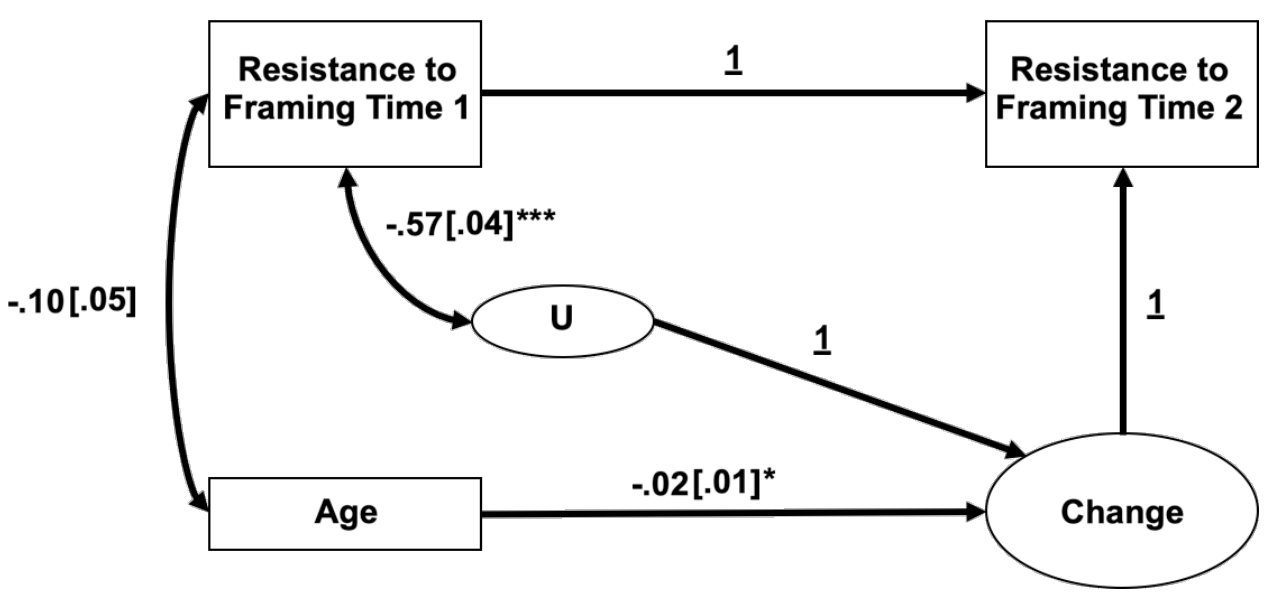

Figure 1. Latent change score model for Resistance to Framing. Underscored coefficients were fixed at 1 for estimation. $U$ is the error of the Change latent variable. Standardized coefficients are followed by bootstrapped standard errors (in square brackets) and significance levels ( ${ }^{*} p<$ $.05, * * p<.01)$.

The model showed good fit with the data $\left(\chi^{2} / \mathrm{df}=2.12\right.$, CFI $=.94$, RMSEA $\left.=.06\right)$. Importantly, the standardized coefficient representing the relationship of age with the slope of change in Resistance to Framing was significant although small (age $\rightarrow$ change $=-.017, p<.05$, $\mathrm{SE}=.007$ and $95 \% \mathrm{CI}$ between -.031 and -.004 computed with the bias-corrected percentile method and 5000 bootstrapping cycles — see also Figure 2, showing a longitudinal performance decrease in older participants but not in younger ones). 


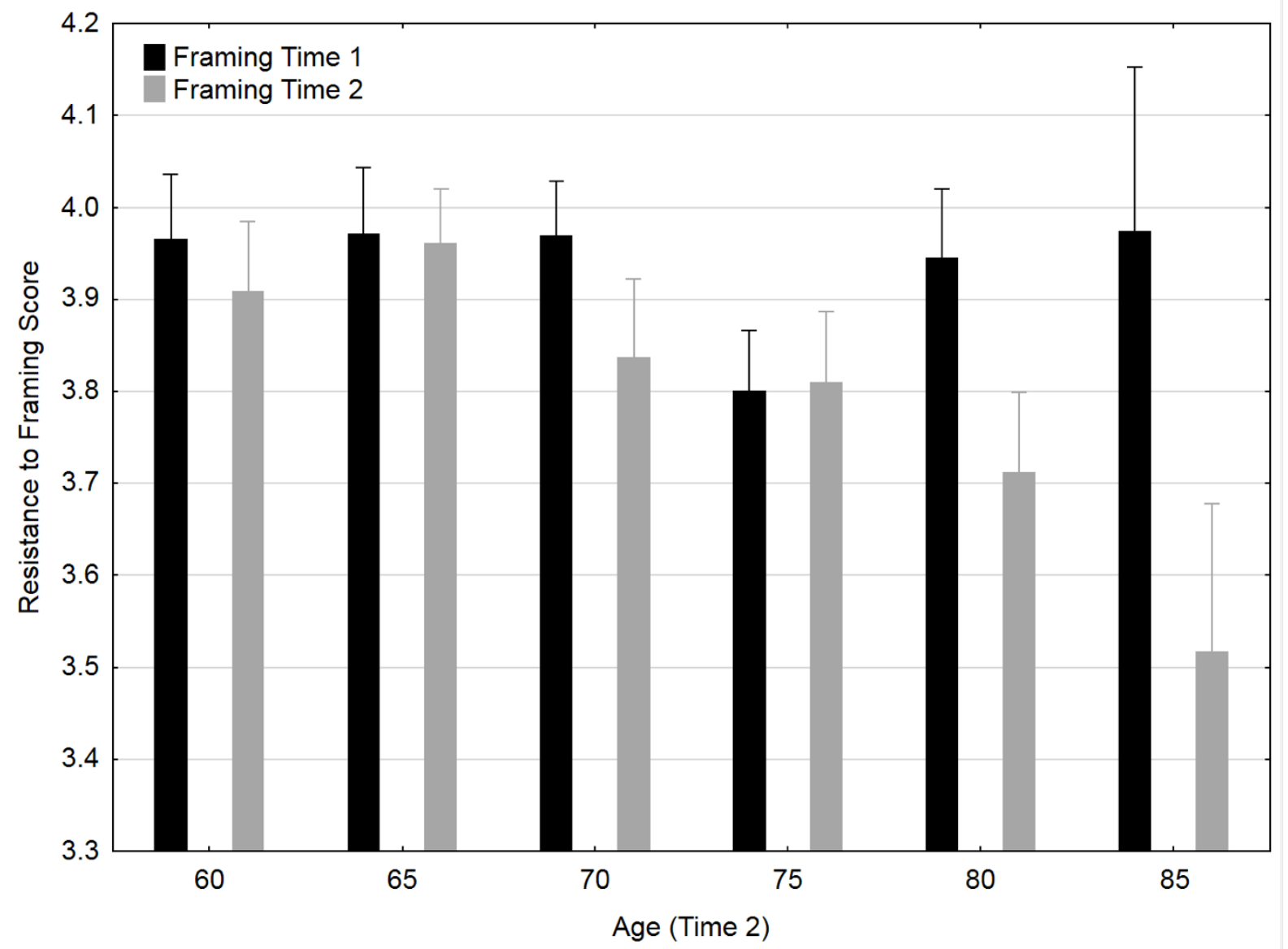

Figure 2. Resistance to Framing score as a function of the testing wave (Time 1, Time 2) and of the age of participants at Time 2. Error bars represent standard errors.

Applying Decision Rules. Age at Time 2 was negatively correlated with performance on Applying Decision Rules $(r=-.39, p<.001)$, but no significant longitudinal difference over five years was detected in the entire sample (paired $t=-0.68, d f=272, p=.50, M_{T 1}=0.72 S D_{T 1}$ $\left.=0.16, M_{T 2}=0.72 S D_{T 2}=0.18\right)$. A latent change score model for Applying Decision Rules, analogous to the one depicted in Figure 1, showed a modest fit to the data $\left(\chi^{2} / \mathrm{df}=4.33, \mathrm{CFI}=\right.$ .98 , RMSEA $=.11)$. The standardized coefficient representing the relationship of age with the slope of change in Applying Decision Rules was not significant (age $\rightarrow$ change $=.004, p=.50$, $\mathrm{SE}=.007$ and $95 \% \mathrm{CI}$ between -.009 and .017 computed with the bias-corrected percentile method and 5000 bootstrapping cycles). Thus, we cannot say that age is associated with the slope of change in this aspect of decision-making competence. The standardized coefficient for 
the relationship between Applying Decision Rules at Time 1 and Age was -.37 $(p=.001, \mathrm{SE}=$ $.05)$ and the one for the relation between Applying Decision Rules at Time 1 and the error term of the Change latent variable was $-.38(p<.001, \mathrm{SE}=.05)$.

Resistance to Sunk Costs. Age at Time 2 was not significantly correlated with performance in Resistance to Sunk Costs $(r=.04, p=.49)$, and no significant longitudinal difference was apparent in the entire sample (paired $t=-0.24$, df $=277, p=.81, M_{T 1}=4.59$ $\left.S D_{T 1}=0.65, M_{T 2}=4.60 S D_{T 2}=0.66\right)$. A latent change score model like the one depicted in Figure 1 showed a very good adaptation to the data $\left(\chi^{2} / \mathrm{df}=.42, \mathrm{CFI}=1, \mathrm{RMSEA}=0\right)$. However, the standardized coefficient representing the relationship of age with the slope of change in Resistance to Sunk Costs was not significant (age $\rightarrow$ change $=.001, p=.86, \mathrm{SE}=.007$ and $95 \% \mathrm{CI}$ between -.012 and .015 computed with the bias-corrected percentile method and 5000 bootstrapping cycles). Thus, age was not associated with the slope of change in Resistance to Sunk Costs. The standardized coefficient for the relation between Resistance to Sunk Costs at Time 1 and Age was $.06(p=.25, \mathrm{SE}=.05)$ and the one for the relation between Resistance to Sunk Costs at Time 1 and the error term of the Change latent variable was $-.51(p<.001, \mathrm{SE}$ $=.04)$.

\section{Cognitive Predictors of Decision-making Competence}

Pairwise correlations between decision-making measures at Time 1 and Time 2 (Table 2) showed significant and moderate positive correlations in decision-making competence across the two testing waves, completed five years apart (Resistance to Framing: $r=.22, p<.001$; Applying Decision Rules: $r=.57, p<.001$; Resistance to Sunk Costs: $r=.46, p<.001$ ), indicating stability over time. At the same time, the within-task correlations for each decisionmaking measure were stronger than the ones between different decision-making measures, with the exception of Resistance to Framing, thus showing task-level specificity. 
Table 2

Pairwise Correlations between the Measures at the First (Time 1) and Second (Time 2) Testing Waves

\begin{tabular}{|c|c|c|c|c|c|c|c|c|c|c|c|c|c|}
\hline & 1 & 2 & 3 & 4 & 5 & 6 & 7 & 8 & 9 & 10 & 11 & 12 & 13 \\
\hline \multicolumn{14}{|l|}{ 1. Sex } \\
\hline 2. Education (years of) & -.10 & & & & & & & & & & & & \\
\hline 3. Resistance to Framing Time 1 & .07 & $.13^{*}$ & & & & & & & & & & & \\
\hline 4. Applying Decision Rules Time 1 & $.17^{* *}$ & $.42 * * *$ & $.17 * *$ & & & & & & & & & & \\
\hline 5. Resistance to Sunk Costs Time 1 & -.07 & .06 & -.05 & .03 & & & & & & & & & \\
\hline 6. Block Design Time 1 & .06 & $.28 * * *$ & $.16^{* *}$ & $.34 * * *$ & .03 & & & & & & & & \\
\hline 7. Vocabulary (SRB) Time 1 & $-.14^{*}$ & $.41 * * *$ & $.16^{* *}$ & $.35^{* * *}$ & .05 & $.31 * * *$ & & & & & & & \\
\hline 8. Age Time 2 & -.01 & $-.36 * * *$ & -.05 & $-.33 * * *$ & .08 & $-.47 * * *$ & $-.17 * *$ & & & & & & \\
\hline 9. MMSE Time 2 & .01 & $.27 * * *$ & $.16^{* *}$ & $.29 * * *$ & .10 & $.34 * * *$ & $.23 * * *$ & $-.14^{*}$ & & & & & \\
\hline 10. Resistance to Framing Time 2 & -.05 & $.28 * * *$ & $.22 * * *$ & $.29 * * *$ & .03 & $.22 * * *$ & $.26 * * *$ & $-.17 * *$ & $.15^{*}$ & & & & \\
\hline 11. Applying Decision Rules Time 2 & $.13^{*}$ & $.45 * * *$ & $.17 * *$ & $.57 * * *$ & .09 & $.37 * * *$ & $.41 * * *$ & $-.39 * * *$ & $.31 * * *$ & $.26 * * *$ & & & \\
\hline 12. Resistance to Sunk Costs Time 2 & .01 & -.01 & .08 & .05 & $.46 * * *$ & .07 & .08 & .04 & .07 & -.02 & $.16^{* *}$ & & \\
\hline 13. Block Design Time 2 & .04 & $.28 * * *$ & .11 & $.35 * * *$ & .06 & $.82 * * *$ & $.30 * * *$ & $-.49 * * *$ & $.35 * * *$ & $.20 * *$ & $.35 * * *$ & .06 & \\
\hline 14. Vocabulary (SRB) Time 2 & -.11 & $.51 * * *$ & $.20 * *$ & $.38 * * *$ & .02 & $.31 * * *$ & $.75^{* * *}$ & $-.19 * *$ & $.32 * * *$ & $.30 * * *$ & $.43 * * *$ & .05 & $.30 * * *$ \\
\hline
\end{tabular}

Note. Abbreviations: Correlations involving sex are point-biserial correlations, with positive values indicating that being male is associated to higher scores in the other variable.

Significance levels are as follows: $* p<.05, * * p<.01, * * * p<.001$. 
Aiming to identify potential cognitive predictors of decision-making competence, we relied on longitudinal path modeling to understand to what extent individual differences in the starting levels of a given aspect of decision-making competence and in fluid and crystallized ability were able to predict individual differences in the same aspect of decision-making competence after five years. A two-wave three-variable longitudinal path model with the structure depicted in Figure 3 was estimated with the maximum likelihood method for each decision-making task.

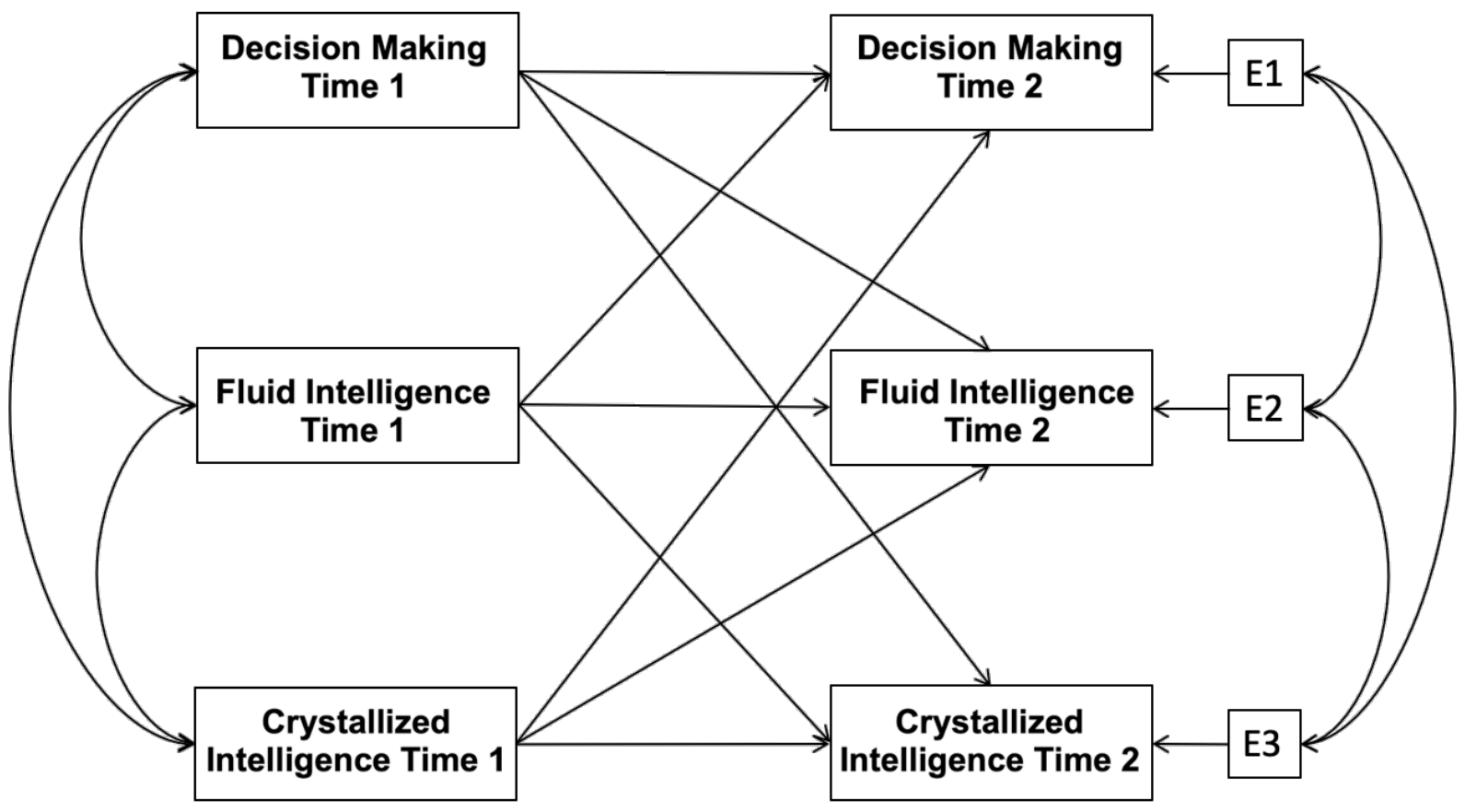

Figure 3. Structure of the two-wave three-variable longitudinal path model estimated for each decision-making task.

Table A1 in the Appendix presents the results of parameter estimation for each of the decision-making measures according to the complete model in Figure 3 (Full Model column). Standard errors computed with 5000 bootstrapping cycles and bias-corrected p-values for statistical tests are reported. The same models were also re-estimated after the removal of nonsignificant coefficients. The results of these reduced models (Figures 4, 5, and 6) were 
stable. That is, parameters common to the models did not differ significantly in complete vs. reduced model versions, with mean differences always smaller than .01 . Moreover, the fit of the reduced longitudinal models was very good: Resistance to Framing $\left(\chi^{2} / \mathrm{df}\right.$ ratio $=1.90, \mathrm{CFI}$ $=.99, \mathrm{RMSEA}=.06)$, Applying Decision Rules $\left(\chi^{2} / \mathrm{df}\right.$ ratio $\left.=1.87, \mathrm{CFI}=.99, \mathrm{RMSEA}=.06\right)$, and Resistance to Sunk Costs $\left(\chi^{2} / \mathrm{df}\right.$ ratio $\left.=.68, \mathrm{CFI}=1, \mathrm{RMSEA}=0\right)$.

Modeling results showed that performance in Resistance to Framing at Time 1 was a significant predictor of performance in the same task at Time 2, after five years (Figure 4). However, fluid and crystallized cognitive abilities at Time 1 also contributed significantly to the longitudinal prediction of Resistance to Framing (conversely, earlier Resistance to Framing did not predict later fluid and crystallized cognitive abilities). Thus, while there was a specific contribution of the earlier level of performance in Resistance to Framing to the prediction of later performance, both fluid and crystallized cognitive skills also contributed.

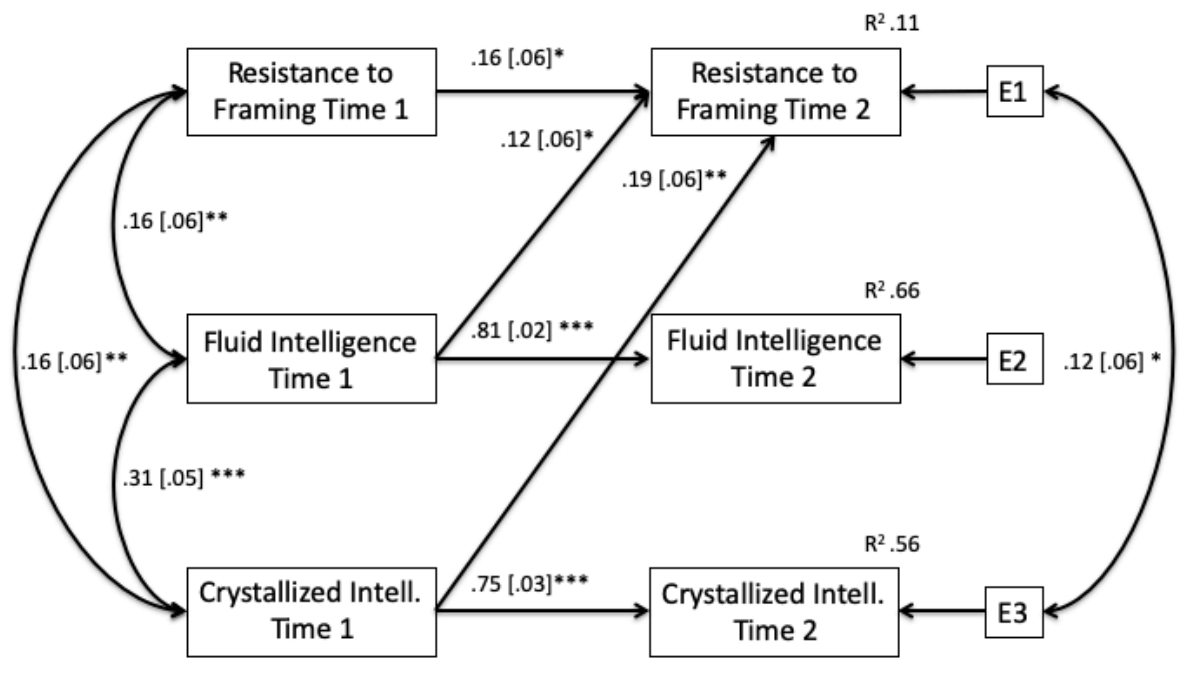

Figure 4. Reduced longitudinal model for Resistance to Framing. Standardized coefficients on the arrows are followed by bootstrapped standard errors (in square brackets) and significance 
levels $(* p<.05, * * p<.01, * * * \mathrm{p}<.001)$. Explained variance $\left(\mathrm{R}^{2}\right)$ for each variable at Time 2 is shown above the respective box.

For Applying Decision Rules, performance at Time 1 was also significantly related with performance at Time 2 (Figure 5), after five years. Moreover, fluid and crystallized cognitive abilities at Time 1 contributed to the prediction of Applying Decision Rules performance at Time 2, although their contributions were smaller. These findings show that the previous level of performance in Applying Decision Rule is (Time 1) the main predictor of later performance in the same task (Time 2), and also highlight the contribution of fluid and crystallized skills.

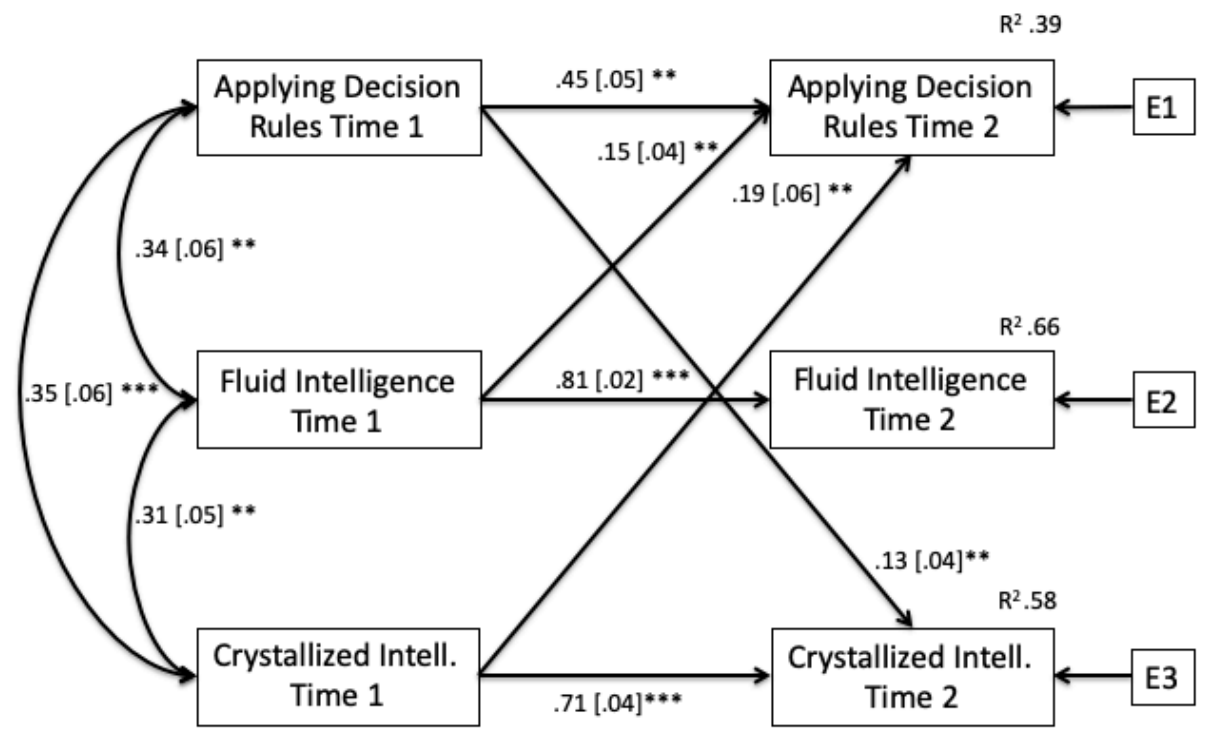

Figure 5. Reduced longitudinal model for Applying Decision Rules. Standardized coefficients on the arrows are followed by bootstrapped standard errors (in square brackets) and significance levels $(* p<.05, * * p<.01, * * * \mathrm{p}<.001)$. Explained variance $\left(\mathrm{R}^{2}\right)$ for each variable at Time 2 is shown above the respective box. 
Performance in Resistance to Sunk Costs at Time 1 predicted performance in the same task at Time 2, five years later (Figure 6). However, in this case, fluid and crystallized skills at Time 1 did not contribute to predict later Resistance to Sunk Costs performance. These findings highlight the predictive role of the initial level of performance in Resistance to Sunk Costs. Additionally, they also suggest that performance in this task is less cognitively laden than performance in Resistance to Framing and Applying Decision Rules.
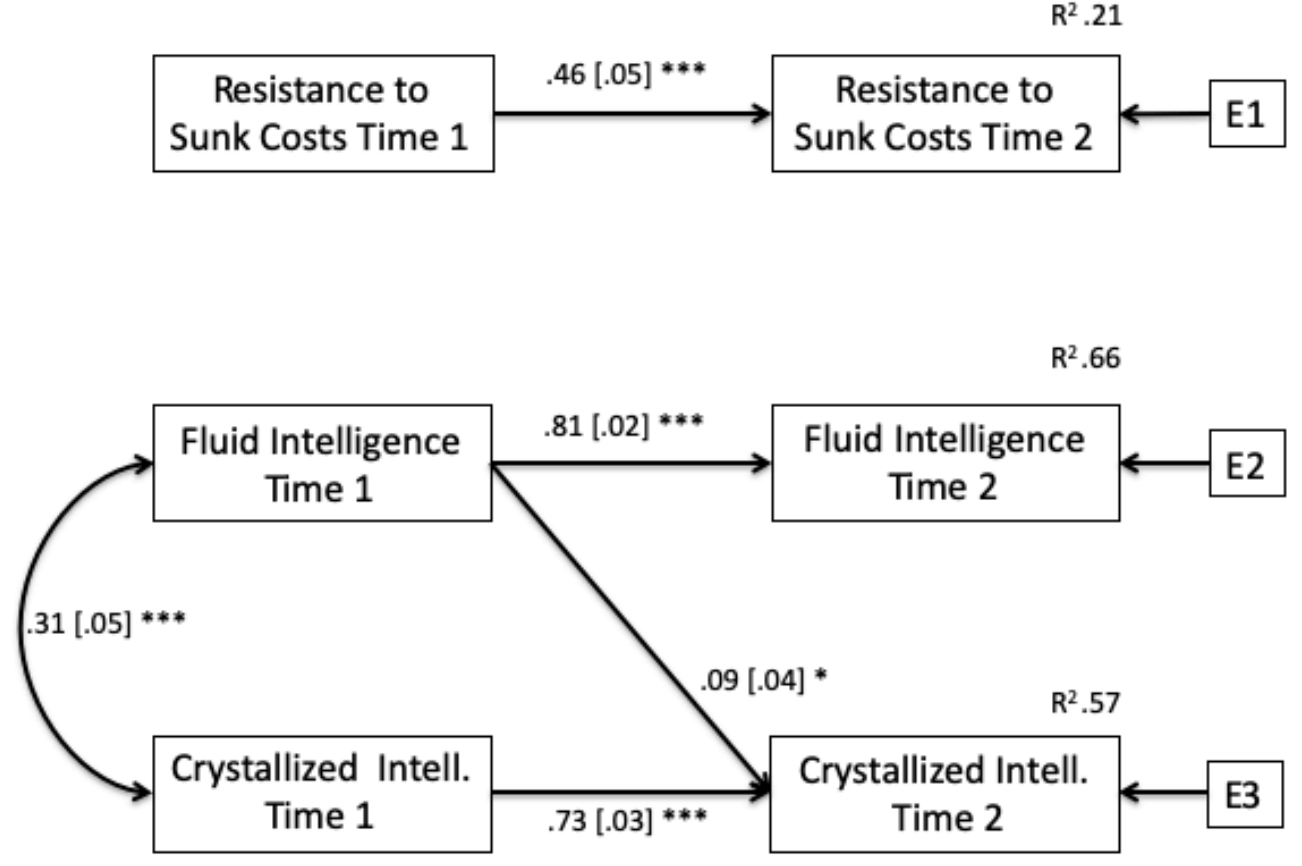

Figure 6. Reduced longitudinal model for Resistance to Sunk Costs. Standardized coefficients on the arrows are followed by bootstrapped standard errors (in square brackets) and significance levels $(* p<.05, * * p<.01, * * * \mathrm{p}<.001)$. Explained variance $\left(\mathrm{R}^{2}\right)$ for each variable at Time 2 is shown above the respective box.

To control for individuals' socio-demographic background, demographic measures (i.e., sex, age, and years of education) were added to the complete models (with directed relations pointing to all Time 2 variables). The results are presented in Table A1 in Appendix (Demographic Control column). The general pattern of findings was confirmed, but fluid 
cognitive skills were no longer significant predictors of Resistance to Framing and Applying Decision Rules. Removing education from the models, due to high standard errors associated with this variable, did not affect the pattern of the results (the coefficients were similar, see Table SM1 in Supplemental Materials). Finally, to address potential concerns about the representativeness of the sample, we also re-estimated the models weighting cases by age and sex according to the Swedish census (2017 data: http://www.scb.se/en/). Census-weighted modeling results were similar to the unweighted ones (see Tables SM2, SM3, and SM4 in Supplemental Materials).

\section{Discussion}

To address the absence of longitudinal research on decision-making competence in older adulthood and the potential limitations of previous cross-sectional investigations, we conducted a study with two aims: (a) to characterize the longitudinal changes in main aspects of decisionmaking competence in a sample of older adults, and (b) to identify longitudinal predictors of the same aspects of decision-making competence in order to identify potential cognitive underpinnings. Below, we discuss the findings of our investigation in relation to these two goals.

\section{Longitudinal Changes in Decision-making Competence}

Our findings showed at most minimal longitudinal decline over five years in our sample of older adults aged 60-85. A slight performance decrease was observed only in Resistance to Framing in participants over 79 years. These findings show that a high level of competence can be preserved in healthy old adulthood, as seen by the overall good level of performance (Table 1). A small longitudinal change seems to occur only in the oldest subgroups of participants in 
our study, thus suggesting declines in decision-making competence relatively late in life for the aspects we considered.

The potential differences between our current longitudinal findings and previous crosssectional results might be explained by a combination of factors: possible boosting effects of cohort-related variables in cross-sectional studies (e.g., Lindenberger et al., 2011; Rönnlund et al., 2005), learning effects in longitudinal assessments like ours (Rönnlund et al., 2005, Salthouse, 2011, 2014b -see also Supplemental Materials), hypothetical decision-making declines occurring earlier than our observed age range, and differences in samples composition. For example, previous studies usually included younger cohorts of participants, although research highlighted longitudinal memory declines within the Betula project for the age range of the present study (Rönnlund et al., 2005). In addition, the correlations between age and decision-making measures in our study are similar to the ones obtained in our previous crosssectional investigation on a sample of 568 Swedish adults 25-80 years of age (Del Missier et al., 2013), for Resistance to Framing and Applying Decision Rules. The exception is Resistance to Sunk Costs, for which a positive correlation with age was found.

Regardless of the potential differences between our results and those of the previous studies, it is important to point out that the age-related differences in our older adult sample are generally not very big. This is the case for both longitudinal changes and differences between age groups (with the exception of Applying Decision Rules in cross-sectional estimates). For Resistance to Framing, the longitudinal decline in performance in a 5 -year period is $-3 \%$, as estimated from mean change scores and considering an initial performance at the top level in our sample (a score of 4 on the test). The cross-sectional estimate of the same 5-year period difference is $-2 \%$, as derived by the differences in mean scores between pairs of cohorts with a 5-year age difference at Time 2 and using the same reference value for the initial performance. Taking the worst cases (i.e., mean change scores in participants older than 79 and difference 
between the 80 and 85 cohorts at Time 2) leads to an estimated longitudinal decline of $-7 \%$ and a cross sectional estimate of $-5 \%$ for a 5 -year period. For Applying Decision Rules, the longitudinal estimated variation for a 5-year period (considering an initial top-level performance of .81) shows a $1 \%$ positive change (possibly due to learning effects in younger participants), while the cross-sectional estimated decline is $-6 \%$. Taking the worst cases by focusing on oldest participants as before, the decline is $-3 \%$ in the longitudinal estimate and $10 \%$ in the cross-sectional estimate. For Resistance to Sunk Costs, the longitudinal change for a 5-year period (considering an initial top-level performance of 4.7) is very close to zero both in the longitudinal and in the cross-sectional estimations (much less than $1 \%$ in absolute value). The worst-case analysis suggests a decline of $-1 \%$ in the longitudinal estimation and of $-5 \%$ in the cross-sectional estimation.

Overall, these findings suggest the potential need to revise our view of older adults' decision-making competence. Specifically, our findings suggest that there is relatively little concern about age-related declines in even cognitively-demanding decision-making tasks, in line with studies underlining not only the weaknesses but also the strengths and the adaptive mechanisms characterizing the aging decision maker (Del Missier et al., 2015; Li, Baldassi, Johnson, \& Weber, 2013; Li et al., 2015; Mata, Schooler, \& Rieskamp, 2007; Salthouse, 2012; Strough et al., 2015).

\section{Cognitive Predictors of Decision-making Competence}

The results of our study show that performance on each investigated decision-making task (at Time 2) is predicted by the initial level of performance on the same task five years earlier (at Time 1), beyond socio-demographic variables, crystallized cognitive skills, and fluid cognitive skills. Indeed, the longitudinal modeling results indicate the utility of decisionmaking constructs, which allowed predicting specific facets of decision performance after five 
years at the individual level (see also Parker et al., 2018). Controlling for demographics, the initial level of decision-making competence is always the stronger predictor of the same aspect of competence five years later.

This indicates that individuals who have acquired or developed relatively better decisionmaking competence by learning or experience may maintain a better performance over time than individuals who have not reached a similar level of competence. These findings suggest the existence of a decision-making reserve, conceptually similar to the cognitive reserve (Stern, 2002) or to the brain maintenance reserve (Nyberg, Lövdén, Riklund, Lindenberger, \& Bäckman, 2012), but specific to decision-making skills. The concept of cognitive reserve was proposed to explain individual differences in resilience to brain damage and it has been used mainly in that context, but it was actually not confined to brain damage: "I propose that this type of reserve is a normal process used by healthy individuals when coping with task demands" (Stern, 2002, p. 450). Cognitive reserve refers to the ability to operate effectively despite a disruption, which can also be related to normal neural and cognitive declines associated with aging. Individuals who are more efficient in information processing in a given task, or can use alternative strategies for carrying out the task, will be less affected by age-related negative changes. In the context of the present study, the construct of decision-making reserve may indicate that some individuals are more efficient in performing some decision-making tasks or they have a broader repertoire of available strategies than others, and this may help them to maintain a better level of decision-making competence despite age-related neural or cognitive declines. The concept of decision-making reserve could be useful to further investigate if there are resources, specific to decision-making competence, which can help individuals to resist traumatic or nontraumatic changes in the brain or in cognitive ability. Moreover, this idea can hopefully stimulate research on how to build and maintain decision-making reserve via teaching 
or training decision-making competence (e.g., Jacobson et al., 2012; Rosi, Vecchi, \& Cavallini, 2019; Zwilling et al., 2019).

In addition to being predicted by the initial level of performance in the same decision task, Resistance to Framing and Applying Decision Rules scores in our study are predicted also by fluid and crystallized cognitive skills. However, in our study crystallized skills contribute more than fluid ones, whereas previous cross-sectional studies including younger adults showed a stronger association with fluid components of cognition. A theoretical implication of these findings is that crystallized abilities may play a greater role in decision-making tasks as the individual ages, possibly because acquired skills and knowledge can partially or totally buffer age-related declines in fluid abilities (cf. Salthouse, 2012, Li et al., 2015). This argument is in line with similar views proposed in recent studies on age differences in decision making (Eberhardt et al., 2019; Li et al., 2015). However, while previous studies mainly focused on the role of domain-specific knowledge and experience (e.g., in the financial or economic domain), our study suggests that general crystallized skills may support older adults' performance in relatively abstract decision-making tasks previously thought to be more associated with fluid components of cognition. This might be explained by older adults' possibly greater reliance on crystallized abilities or knowledge-based strategies in problem understanding and analysis, which can lead to a better understanding of the deep structure of framing problems or to a better comprehension of decision-making rules.

Our previous findings and cognitive aging literature (see e.g. Craik, 1986; Salthouse, 2012) suggest that decision-making tasks with fluid components may require more support in older adults, and performance can benefit from ways to simplify the task. For example, simplified displays highlighting core information and external memories may reduce cognitive load (Del Missier, 2014; Wood et al., 2011). Performance on other decision-making tasks has benefited from providing individuals with the relevant decision principles or metacognitive 
strategies, as well as training to recognize real-world situations in which these principles should be applied (Larrick et al., 1993; Stanovich, 2009). In a similar vein, decisions in knowledgerich domains like economics or health, need to be supported with appropriate domain knowledge when this is missing (e.g., Eberhardt et al., 2017; Li et al., 2015). Our study additionally suggests the need to consider the role of crystallized skills to inform the design of decision support in tasks requiring appropriate understanding and analysis. This could be done by providing simplified descriptions and more exemplification in the stages of problem understanding and analysis, which are stages that may rely more on general crystallized skills possibly buffering age-related declines in fluid abilities.

\section{Limitations and Future Research Directions}

Although our investigation is a first step towards filling the gaps related to the absence of longitudinal research in older adults' decision making, our study is not without limitations that may be addressed by future research. The first limitation is that only two longitudinal observations were available for the analysis and this prevented us from better characterizing the change of target decision-making skills over time through the application of growth models. Two observations with a five-year lag may be too limited for observing major longitudinal changes, even if part of our sample was rather old at the first testing wave and five years are not a short time interval. Therefore, future studies could provide stronger evidence if they traced longitudinal change over a longer time interval and with multiple observations.

The second limitation of our research is represented by the limited number of predictors. Future research may include other cognitive measures (e.g., measures of executive functioning, comprehension, literacy and numeracy, more indicators of fluid and crystallized skills), but also measures of motivation, decision-related experience, and affective skills (possibly relevant for Resistance to Sunk Costs: Bruine de Bruin et al., 2014; Strough et al., 2008). The addition of 
these measures may also help to provide a more empirically-grounded explanation of the influence of crystallized skills in some of the decision-making measures we considered. Moreover, having more predictors of the same constructs may support a latent variable approach that will attenuate task impurity and measurement error (e.g., Miyake et al., 2000). This approach can also be used to deal with another limitation of our study, represented by the rather modest reliability of some of the decision-making measures.

Additionally, we considered only three aspects of decision-making, albeit important. However, decision-making competence is a rich construct that includes aspects not only related to the avoidance of decision biases or to the correct integration of information, but involves also decision problem structuring (e.g., Del Missier, Visentini, \& Mäntylä, 2015), understanding and appraisal of decision-relevant information (Finucane \& Gullion, 2010), assessment of values and beliefs, and metacognitive aspects (Bruine de Bruin et al., 2007; Parker \& Fischhoff, 2005; Stanovich, West, \& Toplak, 2016).

Finally, future research could include younger cohorts of participants in the longitudinal sample, replicate the study in countries with a different socio-demographic background than Sweden, and exert a planned control of learning effects via specific designs (e.g., Salthouse, 2014b).

\section{Conclusion}

Our longitudinal study depicts a generally positive picture of age-related changes in three important aspects of decision-making competence and it shows that starting levels of decisionmaking competence are predictive of decision-making performance over time. In aging societies, these rosy findings and their implications could have important societal relevance. 


\section{References}

Arkes, H. R., \& Blumer, C. (1985). The psychology of sunk cost. Organizational Behavior and Human Decision Processes, 35, 124-140. https://doi.org/10.1016/0749$5978(85) 90049-4$

Besedeš, T., Deck, C., Sarangi, S., \& Shor, M. (2012). Age effects and heuristics in decision making. The Review of Economic and Statistics, 94, 580-595. https://doi.org/10.1162/REST_a_00174

Bruine de Bruin, W., Parker, A. M., \& Fischhoff, B. (2007). Individual differences in Adult Decision-Making Competence. Journal of Personality and Social Psychology, 92, 938956. http://dx.doi.org/10.1037/0022-3514.92.5.938

Bruine de Bruin, W., Parker, A. M., \& Fischhoff, B. (2012). Explaining adult age differences in decision-making competence. Journal of Behavioral Decision Making, 25, 352-360. https://doi.org/10.1002/bdm.712

Bruine de Bruin, W., Strough, J., \& Parker, A. M. (2014). Getting older isn't all that bad: Better decisions and coping when facing "sunk costs". Psychology and Aging, 29, 642-647. http://dx.doi.org/10.1037/a0036308

Craik, F. I. M. (1986). A functional account of age differences in memory. In F. Klix \& H. Hagendorf (Eds.), Human memory and cognitive capabilities: Mechanisms and performances (pp. 409-422). Amsterdam: Elsevier Science Publishers.

Del Missier, F. (2014). Memory and Decision Making: From Basic Cognitive Research to Design Issues. In DMRS (pp. 8-13). http://ceur-ws.org/Vol-1278/paper2.pdf

Del Missier, F., Hansson, P., Parker, A. M., Bruine de Bruin, W., Nilsson, L-G., \& Mäntylä, T. (2017). Unraveling the aging skein: Disentangling sensory and cognitive predictors of age-related differences in decision making. Journal of Behavioral Decision Making, 30, 123-139. https://doi.org/10.1002/bdm.1926 
Del Missier, F., Mäntylä, T., Hansson, P., Bruine de Bruin, W., Parker, A. M., \& Nilsson, LG. (2013). The multifold relationship between memory and decision making: An individual-differences study. Journal of Experimental Psychology: Learning, Memory, and Cognition 39, 1344-1364. https://doi.org/10.1037/a0032379

Del Missier, F., Mäntylä, T., \& Nilsson, L. G. (2015). Aging, memory, and decision making. In T. M. Hess, C. E. Loeckenhoff \& J. N. Strough (Eds.), Aging and decision making: Empirical and applied perspectives, (pp. 127-148). Elsevier Academic Press.

Del Missier, F., Visentini, M., \& Mäntylä, T. (2015). Option generation in decision making: ideation beyond memory retrieval. Frontiers in Psychology, 5, 1584. https://doi.org/10.3389/fpsyg.2014.01584

Dureman, I. (1960). SRB:1. Stockholm, Sweden: Psykologiförlaget.

Eberhardt, W., Bruine de Bruin, W., \& Strough, J. N. (2019). Age differences in financial decision making: The benefits of more experience and less negative emotions. Journal of Behavioral Decision Making, in press. https://doi.org/10.1002/bdm.2097

Edwards, W., (1954). The theory of decision making. Psychological Bulletin, 51, 380-417. http://dx.doi.org/10.1037/h0053870

European Commission (2012). Communication from the Commission to the European Parliament and Council: Taking forward the strategic implementation plan of the European Innovation Partnership on Active and Healthy Ageing. COM(2012) 83FINAL, Brussels.

Fennema, M. G., \& Perkins, J. D. (2008). Mental budgeting versus marginal decision making: training, experience and justification effects on decisions involving sunk costs. Journal of Behavioral Decision Making, 21, 225-239. https://doi.org/10.1002/bdm.585

Finucane, M. L., \& Gullion, C. M. (2010). Developing a tool for measuring the decisionmaking competence of older adults. Psychology and Aging, 25, 271-288. Finucane, M. 
L., \& Gullion, C. M. (2010). Developing a tool for measuring the decision-making competence of older adults. Psychology and aging, 25(2), 271-288. https://doi.org/10.1037/a0019106

Finucane, M. L., Mertz, C. K., Slovic, P., \& Schmidt, E. S. (2005). Task complexity and older adults' decision-making competence. Psychology and Aging, 20, 71-84. http://dx.doi.org/10.1037/0882-7974.20.1.71

Fleischman, D. A., Wilson, R. S., Gabrieli, J. D., Bienias, J. L., \& Bennett, D. A. (2004). A longitudinal study of implicit and explicit memory in old persons. Psychology and Aging, 19, 617-625. http://dx.doi.org/10.1037/0882-7974.19.4.617

Jacobson, D., Parker, A., Spetzler, C., De Bruin, W. B., Hollenbeck, K., Heckerman, D., \& Fischhoff, B., (2012). Improved learning in US history and decision competence with decision-focused curriculum. PLOS ONE, 7(9), e45775.

Josefsson, M., de Luna, X., Pudas, S., Nilsson, L. G., \& Nyberg, L. (2012). Genetic and lifestyle predictors of 15-year longitudinal change in episodic memory. Journal of the American Geriatrics $\quad$ Society, $\quad 60, \quad 2308-2312$. https://doi.org/10.1371/journal.pone.0045775

Kim, S., Goldstein, D., Hasher, L., \& Zacks, R. T. (2005). Framing effects in younger and older adults. The Journals of Gerontology Series B: Psychological Sciences and Social Sciences, 60, 215-218. https://doi.org/10.1093/geronb/60.4.P215

Larrick, R. P., Morgan, J. N., \& Nisbett, R. E. (1990). Teaching the use of cost-benefit reasoning in everyday life. Psychological Science, 1, 362-370. https://doi.org/10.1111/j.1467-9280.1990.tb00243.x

Levin, I. P., \& Gaeth, G. J. (1988). Framing of attribute information before and after consuming the product. Journal of Consumer Research, 15, 374-378. https://doi.org/10.1086/209174 
Li, Y., Baldassi, M., Johnson, E. J., \& Weber, E. U. (2013). Complementary cognitive capabilities, economic decision making, and aging. Psychology and Aging, 28, 595613. http://dx.doi.org/10.1037/a0034172

Li, Y., Gao, J., Enkavi, A. Z., Zaval, L., Weber, E. U., \& Johnson, E. J. (2015). Sound credit scores and financial decisions despite cognitive aging. Proceedings of the National Academies of Sciences USA, 112, 65-69. https://doi.org/10.1073/pnas.1413570112

Lindenberger, U., von Oertzen, T., Ghisletta, P., \& Hertzog, C. (2011). Cross-sectional age variance extraction: What's change got to do with it? Psychology and Aging, 26, 34-47. https://doi.org/10.1037/a0020525

Mata, R., Schooler, L. J., \& Rieskamp, J. (2007). The aging decision maker: cognitive aging and the adaptive selection of decision strategies. Psychology and Aging, 22, 796-810. https://doi.org/10.1037/0882-7974.22.4.796

McArdle, J. J. (2009). Latent variable modeling of differences and changes with longitudinal data. Annual Review of Psychology, 60, 577-605. https://doi.org/10.1146/annurev.psych.60.110707.163612

Miyake, A., Friedman, N. P., Emerson, M. J., Witzki, A. H., Howerter, A., \& Wager, T. D. (2000). The unity and diversity of executive functions and their contributions to complex "frontal lobe" tasks: A latent variable analysis. Cognitive Psychology, 41, 49100. https://doi.org/10.1006/cogp.1999.0734

Nilsson, L-G., Adolsfsson, R., Bäckman, L., de Frias, C. M., Molander, B., \& Nyberg, L. (2004). Betula: A prospective cohort study on memory, health and aging. Aging, Neuropsychology, and Cognition, 11, 134-148. https://doi.org/10.1080/13825580490511026

Nilsson, L-G., Bäckman, L., Erngrund, K., Nyberg, L., Adolsfsson, R., Bucht, G., et al. (1997). The Betula prospective cohort study: Memory, health, and aging. Aging, 
Neuropsychology, and Cognition, 4, 1-32.

https://doi.org/10.1080/13825589708256633

Nyberg, L., Lövdén, M., Riklund, K., Lindenberger, U., \& Bäckman, L. (2012). Memory aging and brain maintenance. Trends in Cognitive Sciences, 16, 292-305. https://doi.org/10.1016/j.tics.2012.04.005

Parker, A. M., Bruine de Bruin, W., Fischhoff, B., \& Weller, J. (2018). Robustness of Decision-Making Competence: Evidence from two measures and an 11-Year Longitudinal Study. Journal of Behavioral Decision Making, 31, 380-391. https://doi.org/10.1002/bdm.2059

Parker, A. M., \& Fischhoff, B. (2005). Decision-making competence: External validation through an individual-differences approach. Journal of Behavioral Decision Making, 18, 1-27. https://doi.org/10.1002/bdm.481

Payne, J. W., Bettman, J. R., \& Johnson, E. J. (1993). The adaptive decision maker. New York: Cambridge University Press.

Rosi, A., Bruine de Bruin, W., Del Missier, F., Cavallini, E., \& Russo, R. (2019). Decisionmaking competence in younger and older adults: which cognitive abilities contribute to the application of decision rules? Aging, Neuropsychology, and Cognition, 26, 174-189. ttps://doi.org/10.1080/13825585.2017.1418283

Rosi, A., Vecchi, T., \& Cavallini, E. (2019). Metacognitive-strategy training promotes decision-making ability in older adults. Open Psychology, 1, 200-214.

Rönnlund, M., \& Nilsson, L-G. (2006). The Betula Study: Reliabilities and long-term stabilities of memory test performances over the adult lifespan. Baltic Journal of Psychology, 7, 6-14.

Rönnlund, M., Nyberg, L., Bäckman, L., \& Nilsson, L-G. (2005). Stability, growth, and decline in adult life span development of declarative memory: Cross-sectional and longitudinal 
data from a population-based study. Psychology and Aging, 20, 3-18. https://doi.org/10.1037/0882-7974.20.1.3

Salthouse, T. A. (2011). All data collection and analysis methods have limitations: Reply to Rabbitt (2011) and Raz and Lindenberger (2011). Psychological Bulletin, 137, 796799. https://doi.org/10.1037/a0024843

Salthouse, T. A. (2012). Consequences of age-related cognitive declines. Annual Review of Psychology, 63, 201-226. https://doi.org/10.1146/annurev-psych-120710-100328

Salthouse, T. A. (2014a). Correlates of cognitive change. Journal of Experimental Psychology: General, 143, 1026-1048. https://doi.org/10.1037/a0034847

Salthouse, T. A. (2014b). Why are there different age relations in cross-sectional and longitudinal comparisons of cognitive functioning? Current directions in Psychological Science, 23, 252-256. https://doi.org/10.1177/0963721414535212

Schaie, K. W. (2013). Developmental influences on adult intelligence: The Seattle Longitudinal Study (2nd ed.). New York, NY: Oxford University Press.

Schneider, S. L. (1992). Framing and conflict: Aspiration level contingency, the status quo, and current theories of risky choice. Journal of Experimental Psychology: Learning, Memory, and Cognition, 18, 1040-1057. https://doi.org/10.1037/0278-7393.18.5.1040

Stanovich, K. E. (2009). Distinguishing the reflective, algorithmic, and autonomous minds: Is it time for a tri-process theory? In J. Evans \& K. Frankish (Eds.), In two minds: Dual processes and beyond (pp. 55-88). New York: Oxford University Press.

Stanovich, K. E., West, R. F., \& Toplak, M. E. (2016). The rationality quotient: Toward a test of rational thinking. Cambridge, MA: MIT press.

Stern, Y. (2002). What is cognitive reserve? Theory and research application of the reserve concept. Journal of the International Neuropsychological Society, 8, 448-460. https://doi.org/10.1017/S1355617702813248 
Strough, J. N., Mehta, C. M., McFall, J. P., \& Schuller, K. L. (2008). Are older adults less subject to the sunk-cost fallacy than younger adults? Psychological Science, 19, 650652. https://doi.org/10.1111/j.1467-9280.2008.02138.x

Strough, J. N., Parker, A. M., Bruine de Bruin, W. (2015). Understanding life-span developmental changes in decision making competence. In T. M. Hess, C. E. Loeckenhoff, \& J. N. Strough (Eds.), Aging and decision making: Empirical and applied perspectives (pp. 235-257). Elsevier Academic Press.

Tombaugh, T. N., \& McIntyre, N. J. (1992). The mini-mental state examination: a comprehensive review. Journal of the American Geriatrics Society, 40, 922-935. https://doi.org/10.1111/j.1532-5415.1992.tb01992.x

Tversky, A. (1972). Elimination by Aspects: A Theory of Choice. Psychological Review, 79, 281-299.

Tversky, A., \& Kahneman, D. (1981). The framing of decisions and the psychology of choice. Science, 211, 453-458. https://doi.org/10.1126/science.7455683

United Nations (2017). World Population Ageing. United Nations, Department of Economic and Social Affairs, Population Division - Highlights (ST/ESA/SER.A/397).

Wechsler, D. (1981). Wechsler adult intelligence scale - revised: Manual. New York: Psychological Corporation.

Wood, S., Hanoch, Y., Barnes, A., Liu, P. J., Cummings, J., Bhattacharya, C., \& Rice, T. (2011). Numeracy and Medicare Part D: The importance of choice and literacy for numbers in optimizing decision making for Medicare's prescription drug program. Psychology and Aging, 26, 295-307. http://dx.doi.org/10.1037/a0022028

Zwilling, C. E., Daugherty, A. M., Hillman, C. H., Kramer, A. F., Cohen, N. J., \& Barbey, A. K., (2019). Enhanced decision-making through multimodal training. NPJ science of learning, 4, 1-10. https://doi.org/10.1038/s41539-019-0049-x 
Appendix

Table A1

Longitudinal Path Models for Decision-making Measures (Full Models and Models with Demographic Control)

\begin{tabular}{|c|c|c|c|c|c|c|}
\hline \multirow[b]{3}{*}{ Estimate } & \multicolumn{2}{|c|}{ Resistance to Framing } & \multicolumn{2}{|c|}{ Applying Decision Rules } & \multicolumn{2}{|c|}{ Resistance to Sunk Costs } \\
\hline & Full Model & Demographic & Full Model & Demographic & Full Model & Demographic \\
\hline & & Control & & Control & & Control \\
\hline \multicolumn{7}{|l|}{ Relation in the model } \\
\hline DMC Time 1 --> DMC Time 2 & $.17[.06] * *$ & $.17[.06] * *$ & $.45[.05] * *$ & $.38[.06] * * *$ & $.45[.05] * * *$ & $.45[.05]^{* * *}$ \\
\hline Fluid Time 1 --> DMC Time 2 & $.14[.06] *$ & $.10[.07]$ & $.15[.04] * *$ & $.07[.05]$ & $.04[.06]$ & $.06[.07]$ \\
\hline Crystallized Time 1 --> DMC Time 2 & $.18[.06] * *$ & $.12[.07]$ & $.19[.06] * *$ & $.20[.07] * *$ & $.04[.06]$ & $.07[.06]$ \\
\hline DMC 1 --> Fluid Time 2 & $-.03[.04]$ & $-.03[.04]$ & $.07[.04]$ & $.05[.04]$ & $.03[.04]$ & $.05[.04]$ \\
\hline Fluid Time 1 --> Fluid Time 2 & $.80[.02] * * *$ & $.77[.03] * * *$ & $.78[.03] * * *$ & $.76[.03] * * *$ & $.79[.02] * * *$ & $.77[.03] * * *$ \\
\hline Crystallized Time 1 --> Fluid Time 2 & $.06[.04]$ & $.06[.04]$ & $.04[.04]$ & $.04[.04]$ & $.06[.04]$ & $.05[.04]$ \\
\hline DMC Time 1 --> Crystallized Time 2 & $.08[.04]$ & $.07[.04]$ & $.11[.04] *$ & $.07[.06]$ & $-.02[.04]$ & $-.04[.04]$ \\
\hline Fluid Time 1 --> Crystallized Time 2 & $.08[.04]$ & $.05[.05]$ & $.06[.04]$ & $.05[.05]$ & $.09[.04] *$ & $.07[.05]$ \\
\hline Crystallized Time 1 --> Crystallized Time 2 & $.72[.03] * * *$ & $.68[.04] * * *$ & $.69[.04] * * *$ & $.67[.04] * * *$ & $.73[.03] * * *$ & $.69[.04] * * *$ \\
\hline Age --> DMC Time 2 & --- & $-.03[.07]$ & --- & $-.17[.05] * *$ & --- & $.02[.07]$ \\
\hline Age --> Fluid Time 2 & --- & $-.14[.05] * *$ & --- & $-.13[.05] * *$ & --- & $-.15[.05] * *$ \\
\hline Age --> Crystallized Time 2 & --- & $.02[.05]$ & --- & $.04[.05]$ & --- & $.03[.05]$ \\
\hline Education --> DMC Time 2 & --- & $.17[1.06]^{* *}$ & --- & $.15[1.05] * *$ & --- & $-.06[1.06]$ \\
\hline Education --> Fluid Time 2 & --- & $.01[1.04]$ & --- & $-.01[1.04]$ & --- & $.00[1.04]$ \\
\hline Education --> Crystallized Time 2 & --- & $.25[1.04] * * *$ & --- & $.24[1.05]^{* * *}$ & --- & $.26[1.05]^{* * *}$ \\
\hline Sex --> DMC Time 2 & --- & $-.04[.06]$ & --- & $.11[.05] *$ & --- & $.05[.05]$ \\
\hline Sex --> Fluid Time 2 & --- & $.01[.04]$ & --- & $-.01[.04]$ & --- & $.01[.04]$ \\
\hline
\end{tabular}


Sex --> Crystallized Time 2

DMC Time $1<-->$ Fluid Time 1

DMC Time $1<-$-> Crystallized Time 1

Fluid Time $1<-->$ Crystallized Time 1

E1 <--> E2

E2 <--> E3

E1 <--> E3

Explained variance
$--$

$\begin{array}{lll}.16[.06]^{* *} & .16[.06]^{* *} & .34[.05]^{* *} \\ .16[.06]^{* *} & .16[.06]^{* *} & .35[.05]^{* *} \\ .31[.05]^{* * *} & .31[.05]^{* * *} & .31[.05]^{* * *} \\ .02[.06] & .00[.06] & .02[.05] \\ .04[.07] & .03[.07] & .02[.07] \\ .12[.06]^{*} & .08[.06] & .11[.06]\end{array}$

$-.01[.04]$
$.34[.05]^{* *}$
$.35[.05]^{* *}$
$.31[.05]^{* * *}$
$-.01[.06]$
$.02[.07]$
$.07[.06]$

$--$

$.03[.06]$

.05 [.06]

$.31[.05]^{* * *}$

$-.03[.06]$

$.04[.07]$

$-.01[.06]$
$.00[.04]$

$.03[.06]$

$.05[.06]$

$.31[.05]^{* * *}$

$-.02[.06]$

$.03[.07]$

$.01[.06]$

$\mathrm{R}^{2}$ DMC Time 2

$\mathrm{R}^{2}$ Fluid Time 2

.11

.39

$\mathrm{R}^{2}$ Crystallized Time 2

Note. Abbreviations: DMC $=$ Decision-making competence measure, as indicated in the specific column, Fluid $=$ Block Design, Crystallized $=$ SRB, E1 $=$ error term in Resistance to Framing at Time 2, E2 = error term in Block Design at Time 2, E3 = error term in SRB at Time 2. Values in each column represent standardized coefficients, bootstrapped standard errors (in square brackets), and significance levels $\left(* p<.05,{ }^{* *} p<.01, * * * p<.001\right.$ ). Demographic control models include a correlation between Age and Education not shown in the table $\left(-.36, p<.001\right.$ for each model). The final three rows of the table show the explained variance $\left(\mathrm{R}^{2}\right)$ in Time 2 variables. 
Supplemental Materials for the paper

Decision-making Competence in Older Adults: A Rosy View from a Longitudinal Investigation 
Table SM1

Longitudinal Path Models for Decision-making Competence Measures with Demographic Control but Excluding Education

$\begin{array}{ccc}\text { Estimate } & \text { Resistance to } & \text { Applying Decision } \\ \text { Framing Model } & \text { Rules Model } & \text { Costs Model }\end{array}$

\begin{tabular}{|c|c|c|c|}
\hline \multicolumn{4}{|l|}{ Relation in the model } \\
\hline DMC Time 1 --> DMC Time 2 & $.18[.06] * *$ & $.41[.05] * *$ & $.45[.04] * * *$ \\
\hline Fluid Time 1 --> DMC Time 2 & $.11[.07]$ & $.07[.05]$ & $.05[.07]$ \\
\hline Crystallized Time 1 --> DMC Time 2 & $.17[.07] * *$ & $.23[.06] * *$ & $.05[.06]$ \\
\hline DMC Time 1 --> Fluid Time 2 & $-.03[.04]$ & $.05[.04]$ & $.05[.04]$ \\
\hline Fluid Time 1 --> Fluid Time 2 & $.77[.03] * * *$ & $.76[.03] * * *$ & $.77[.03] * * *$ \\
\hline Crystallized Time 1 --> Fluid Time 2 & $.06[.04]$ & $.04[.04]$ & $.06[.04]$ \\
\hline DMC Time 1 --> Crystallized Time 2 & $.08[.04]$ & $.12[.05] *$ & $-.02[.04]$ \\
\hline Fluid Time 1 --> Crystallized Time 2 & $.06[.05]$ & $.05[.05]$ & $.07[.05]$ \\
\hline Crystallized Time 1 --> Crystallized Time 2 & $.72[.04] * * *$ & $.69[.04] * * *$ & $.73[.03] * * *$ \\
\hline Age --> DMC Time 2 & $-.08[.07]$ & $-.20[.05] * * *$ & $.04[.06]$ \\
\hline Age --> Fluid Time 2 & $-.14[.05] * *$ & $-.13[.05] * *$ & $-.15[.05] * *$ \\
\hline Age --> Crystallized Time 2 & $-.04[.04]$ & $-.01[.05]$ & $-.04[.04]$ \\
\hline Sex --> DMC Time 2 & $-.05[.06]$ & $.09[.05]$ & $.05[.05]$ \\
\hline Sex --> Fluid Time 2 & $.01[.04]$ & $-.01[.04]$ & $.01[.04]$ \\
\hline Sex --> Crystallized Time 2 & $-.02[.04]$ & $-.04[.04]$ & $-.01[.04]$ \\
\hline DMC Time $1<-->$ Fluid Time 1 & $.16[.06] * *$ & $.34[.06] * *$ & $.03[.06]$ \\
\hline DMC Time $1<-->$ Crystallized Time 1 & $.16[.06] * *$ & $.35[.06] * *$ & $.05[.06]$ \\
\hline Fluid Time $1<-->$ Crystallized Time 1 & $.31[.05] * * *$ & $.31[.05] * * *$ & $.31[.05] * * *$ \\
\hline E1 $<-->$ E2 & $.01[.06]$ & $-.01[.06]$ & $-.02[.06]$ \\
\hline E2 $<-->$ E3 & $.03[.07]$ & $.01[.07]$ & $.03[.07]$ \\
\hline E1 <--> E3 & $.12[.06] *$ & $.12[.06]$ & $-.01[.06]$ \\
\hline
\end{tabular}

Explained variance

$\begin{array}{llll}\mathrm{R}^{2} \text { DMC Time 2 } & .11 & .37 & .22 \\ \mathrm{R}^{2} \text { Fluid Time 2 } & .64 & .65 & .64 \\ \mathrm{R}^{2} \text { Crystallized Time 2 } & .57 & .58 & .57\end{array}$

Note . DMC = Decision-making competence measure (see the specific column header), Fluid = Block Design, Crystallized $=\mathrm{SRB}, \mathrm{E} 1=$ error term in DMC at Time 2, E2 = error term in Block Design at Time 2, E3 = error term in SRB at Time 2. Values in each column represent standardized coefficients, bootstrapped standard errors (in square brackets) and significance levels $(* p<.05, * * p<.01, * * * p<.001)$. The final three rows of the table show the explained variance $\left(\mathrm{R}^{2}\right)$ in Time 2 variables. 


\section{Table SM2}

Longitudinal Path Model for Resistance to Framing Weighted for 2017 Swedish Census

\begin{tabular}{|c|c|c|c|}
\hline Estimate & $\begin{array}{l}\text { Standardized } \\
\text { Coefficient }\end{array}$ & $\begin{array}{l}\text { Standard } \\
\text { Error }\end{array}$ & $\begin{array}{c}\text { Significance } \\
\text { Level }\end{array}$ \\
\hline \multicolumn{4}{|l|}{ Relation in the model } \\
\hline Resistance to Framing Time 1 --> Resistance to Framing Time 2 & .18 & .06 & $p<.01$ \\
\hline Fluid Skills Time 1 --> Resistance to Framing Time 2 & .16 & .06 & $p<.01$ \\
\hline Crystallized Skills Time 1 --> Resistance to Framing Time 2 & .20 & .06 & $p<.01$ \\
\hline Resistance to Framing Time 1 --> Fluid Skills Time 2 & -.06 & .04 & \\
\hline Fluid Skills Time 1 --> Fluid Skills Time 2 & .80 & .02 & $p<.001$ \\
\hline Crystallized Skills Time 1 --> Fluid Skills Time 2 & .09 & .04 & $p<.05$ \\
\hline Resistance to Framing Time 1 --> Crystallized Skills Time 2 & .09 & .04 & $p<.05$ \\
\hline Fluid Skills Time 1 --> Crystallized Skills Time 2 & .07 & .04 & \\
\hline Crystallized Skills Time 1 --> Crystallized Skills Time 2 & .72 & .03 & $p<.001$ \\
\hline Resistance to Framing Time $1<-->$ Fluid Skills Time 1 & .15 & .06 & $p<.01$ \\
\hline Resistance to Framing Time $1<-->$ Crystallized Skills Time 1 & .12 & .06 & \\
\hline Fluid Skills Time $1<-->$ Crystallized Skills Time 1 & .31 & .05 & $p<.001$ \\
\hline E1 $<-->$ E2 & .05 & .06 & \\
\hline $\mathrm{E} 2<-->\mathrm{E} 3$ & .02 & .06 & \\
\hline E1 $<-->$ E3 & .11 & .06 & \\
\hline \multicolumn{4}{|l|}{ Explained Variance } \\
\hline $\mathrm{R}^{2}$ Resistance to Framing Time 2 & .14 & & \\
\hline $\mathrm{R}^{2}$ Fluid Skills Time 2 & .67 & & \\
\hline $\mathrm{R}^{2}$ Crystallized Skills Time 2 & .57 & & \\
\hline
\end{tabular}

Note. Fluid Skills $=$ Block Design, Crystallized Skills $=$ SRB Vocabulary, E1 $=$ error term in Resistance to Framing at Time 2, E2 $=$ error term in Block Design at Time 2, E3 = error term in SRB at Time 2. The final three rows of the table show the explained variance $\left(\mathrm{R}^{2}\right)$ in Time 2 variables. 
Table SM3

Longitudinal Path Model for Applying Decision Rules Weighted for 2017 Swedish Census

\begin{tabular}{|c|c|c|c|}
\hline Estimate & $\begin{array}{c}\text { Standardized } \\
\text { Coefficient }\end{array}$ & $\begin{array}{c}\text { Standard } \\
\text { Error }\end{array}$ & $\begin{array}{c}\text { Significance } \\
\text { Level }\end{array}$ \\
\hline \multicolumn{4}{|l|}{ Relation in the model } \\
\hline Applying Decision Rules Time 1 --> Applying Decision Rules Time 2 & .45 & .05 & $p<.001$ \\
\hline Fluid Skills Time 1 --> Applying Decision Rules Time 2 & .17 & .05 & $p<.01$ \\
\hline Crystallized Skills Time 1 --> Applying Decision Rules Time 2 & .20 & .05 & $p<.001$ \\
\hline Applying Decision Rules Time 1 --> Fluid Skills Time 2 & .07 & .04 & \\
\hline Fluid Skills Time 1 --> Fluid Skills Time 2 & .77 & .03 & $p<.001$ \\
\hline Crystallized Skills Time 1 --> Fluid Skills Time 2 & .06 & .04 & \\
\hline Applying Dec. Rules Time 1 --> Crystallized Skills Time 2 & .11 & .04 & $p<.05$ \\
\hline Fluid Skills Time 1 --> Crystallized Skills Time 2 & .05 & .04 & \\
\hline Crystallized Skills Time 1 --> Crystallized Skills Time 2 & .69 & .03 & $p<.001$ \\
\hline Applying Decision Rules Time 1 <--> Fluid Skills Time 1 & .35 & .05 & $p<.001$ \\
\hline Applying Decision Rules Time $1<-->$ Crystallized Skills Time 1 & .35 & .05 & $p<.001$ \\
\hline Fluid Skills Time $1<-->$ Crystallized Skills Time 1 & .31 & .06 & $p<.001$ \\
\hline E1 $<-->$ E2 & .02 & .06 & \\
\hline E2 $<-->$ E3 & -.01 & .06 & \\
\hline E1 $<-->$ E3 & .12 & .06 & $p<.05$ \\
\hline \multicolumn{4}{|l|}{ Explained Variance } \\
\hline $\mathrm{R}^{2}$ Applying Decision Rules Time 2 & .41 & & \\
\hline $\mathrm{R}^{2}$ Fluid Skills Time 2 & 67 & & \\
\hline $\mathrm{R}^{2}$ Crystallized Skills Time 2 & .57 & & \\
\hline
\end{tabular}

Note. Fluid Skills $=$ Block Design, Crystallized Skills $=$ SRB Vocabulary, E1 $=$ error term in Applying Decision Rules at Time 2, E2 = error term in Block Design at Time 2, E3 = error term in SRB at Time 2. The final three rows of the table show the explained variance $\left(\mathrm{R}^{2}\right)$ in Time 2 variables. 
Table SM-4

Longitudinal Path Model for Resistance to Sunk Costs Weighted for 2017 Swedish Census

\begin{tabular}{|c|c|c|c|}
\hline Estimate & $\begin{array}{c}\text { Standardized } \\
\text { Coefficient }\end{array}$ & $\begin{array}{c}\text { Standard } \\
\text { Error }\end{array}$ & $\begin{array}{c}\text { Significance } \\
\text { Level }\end{array}$ \\
\hline \multicolumn{4}{|l|}{ Relation in the model } \\
\hline Resistance to Sunk Costs Time 1 --> Resistance to Sunk Costs Time 2 & .43 & .05 & $p<.001$ \\
\hline Fluid Skills Time 1 --> Resistance to Sunk Costs Time 2 & .05 & .06 & \\
\hline Crystallized Skills Time 1 --> Resistance to Sunk Costs Time 2 & .04 & .06 & \\
\hline Resistance to Sunk Costs Time 1 --> Fluid Skills Time 2 & .05 & .04 & \\
\hline Fluid Skills Time 1 --> Fluid Skills Time 2 & .79 & .02 & $p<.01$ \\
\hline Crystallized Skills Time 1 --> Fluid Skills Time 2 & .08 & .04 & $p<.05$ \\
\hline Resistance to Sunk Costs Time 1 --> Crystallized Skills Time 2 & -.03 & .04 & \\
\hline Fluid Skills Time 1 --> Crystallized Skills Time 2 & .08 & .04 & \\
\hline Crystallized Skills Time 1 --> Crystallized Skills Time 2 & .73 & .03 & $p<.001$ \\
\hline Resistance to Sunk Costs Time $1<-->$ Fluid Skills Time 1 & .02 & .06 & \\
\hline Resistance to Sunk Costs Time $1<-->$ Crystallized Skills Time 1 & .08 & .06 & \\
\hline Fluid Skills Time $1<-->$ Crystallized Skills Time 1 & .31 & .06 & $p<.001$ \\
\hline E1 $<-->$ E2 & -.07 & .06 & \\
\hline E2 $<-->$ E3 & .01 & .06 & \\
\hline E1 $<-->$ E3 & .02 & .06 & \\
\hline \multicolumn{4}{|l|}{ Explained Variance } \\
\hline $\mathrm{R}^{2}$ Resistance to Sunk Costs Time 2 & .19 & & \\
\hline $\mathrm{R}^{2}$ Fluid Skills Time 2 & 67 & & \\
\hline $\mathrm{R}^{2}$ Crystallized Skills Time 2 & .56 & & \\
\hline
\end{tabular}

Note. Fluid Skills $=$ Block Design, Crystallized Skills $=$ SRB Vocabulary, E1 $=$ error term in Resistance to Sunk Costs at Time 2, E2 = error term in Block Design at Time 2, E3 = error term in SRB at Time 2. The final three rows of the table show the explained variance $\left(\mathrm{R}^{2}\right)$ in Time 2 variables. 


\section{Learning Effects}

Learning effects were assessed by comparing participants who completed the decision-making tests in both the fifth and sixth waves (i.e. the sample of the investigation reported in this paper) with a similar subset of participants who completed the decision-making tests in only in the sixth Betula wave (and had not been previously tested in the fifth wave, $\mathrm{n}=107$, age between 60 and $85, \mathrm{M}=$ 69.16, $\mathrm{SD}=7.25)$. Participants tested twice $(M=3.83, S D=.03)$ did not show a better performance in Resistance to Framing than participants tested once $(M=3.76, S D=.06), F(1,377)=1.22, p=$ $\left..27, \eta^{2}=.00\right)$ even after controlling for age as a covariate, $F(1,376)=1.89, p=.17, \eta^{2}=.01$. Participants tested twice $(M=.72, S D=.01)$ showed a better performance in Applying Decision Rules than participants tested once $(M=.66, S D=.02), F(1,367)=8.97, p<.01, \eta^{2}=.02$, even after controlling for age as a covariate, $F(1,366)=18.92, p<.001, \eta^{2}=.05$. There was no learning effect in Resistance to Sunk Costs, $F(1,380)=0.23, p=.63, \eta^{2}=.00$, with no difference between participants tested once $(M=4.64, S D=.06)$ vs twice $(M=4.60, S D=.04)$, even after controlling for age as a covariate, $F(1,379)=0.27, p=.60, \eta^{2}=.00$. 